\title{
Decreased Presynaptic Sensitivity to Adenosine after Cocaine Withdrawal
}

\author{
Olivier Manzoni, ${ }^{1,2}$ Didier Pujalte, ${ }^{1}$ John Williams, ${ }^{2}$ and Joël Bockaert ${ }^{1}$ \\ ${ }^{1}$ Centre National de la Recherche Scientifique, Unité Propre de Recherches 9023, 34094 Montpellier Cedex 05, France, \\ and 2Vollum Institute, Oregon Health Sciences University, Portland, Oregon 97201.
}

\begin{abstract}
The nucleus accumbens (NAc) is a site mediating the rewarding properties of drugs of abuse, such as cocaine, amphetamine, opiates, nicotine, and alcohol (Wise and Bozarth, 1987; Koob, 1992; Samson and Harris, 1992; Woolverton and Johnson, 1992; Self and Nestler, 1995; Pontieri et al., 1996). Acute cocaine has been shown to decrease excitatory synaptic transmission mediated by the cortical afferents to the NAc (Nicola et al., 1996), but the effects of long-term cocaine treatment and withdrawal have not been explored. Here, we report that longterm (1 week) withdrawal from chronic cocaine reduced the potency of adenosine to presynaptically inhibit glutamate (Glu) release by activating adenosine $A 1$ receptors. Adenosine A1 receptors were not desensitized, because the potency of the
\end{abstract}

metabolically stable adenosine analog $\mathrm{N}^{6}$-cyclopentyladenosine was unchanged after chronic cocaine withdrawal. When adenosine transporters were blocked, the potency of adenosine to inhibit Glu release from naive and cocainewithdrawn NAc slices was similar. These results suggest that one of the long-term consequences of cocaine withdrawal is an augmented uptake of adenosine. This long-lasting change expressed at the presynaptic excitatory inputs to the medium spiny output neurons in the NAc may help identify new therapeutic targets for the treatment of drug abuse.

Key words: nucleus accumbens; chronic cocaine; adenosine; transporter; withdrawal; drug abuse
The nucleus accumbens (NAc) is essential to the reinforcing properties of cocaine and all other addictive drugs (Hyman, 1996; Koob, 1996). The vast majority of cells in the NAc are GABAergic medium spiny neurons that have a very negative resting membrane potential in brain slices in vivo as in vitro. In addition, medium spiny neurons of the NAc are interconnected by a dense network of recurrent collaterals and therefore depend on glutamatergic excitatory afferents to generate action potentials (Smith and Bolam, 1990; Pennartz et al., 1994). Acute and chronic treatment with psychostimulants affect both dopamine (DA) levels (Kalivas and Duffy, 1990; Self and Nestler, 1995) and glutamatergic transmission (Nie et al., 1994; Pierce et al., 1996) in the NAc. Slice experiments (Pennartz et al., 1990) have shown that excitatory cortical afferents to the NAc express long-term potentiation (Pennartz et al., 1993; Kombian and Malenka, 1994). Psychostimulants, such as cocaine and amphetamine, decrease excitatory synaptic transmission to the NAc via the activation of dopamine D1-like receptors (Nicola et al., 1996). DA receptor inhibition of glutamate (Glu) release could be mediated by either direct presynaptic D1 receptors activation (Nicola et al., 1996) or postsynaptic interaction between dopamine D1 and NMDA receptors, causing the release of adenosine that then acts on pre-

\footnotetext{
Received May 15, 1998; revised July 8, 1998; accepted July 14, 1998.

This research was supported by grants from the Centre National de la Recherche Scientifique, Institut National de la Santé et de la Recherche Médicale, Communauté Economique Européenne Biotech and Biomed, the Bayer Company, Fondation Simone et Cino Del Ducca, the National Institute on Drug Abuse-INVEST program, and National Institute on Drug Abuse Grant DA04523. The authors would like to thank M. Passama for the artwork, Jean-Marie Michel for writing the mEPSCs acquisition and analysis software, and Drs. M. Kavanaugh and J. Brundege for critical reading of this manuscript.

Correspondence should be addressed to Dr. Olivier Manzoni, Oregon Health Sciences University L-474, 3181 S.W. Sam Jackson Park Road, Portland, Oregon 97201.

Copyright (ㄷ) 1998 Society for Neuroscience $\quad 0270-6474 / 98 / 187996-07 \$ 05.00 / 0$
}

synaptic adenosine A1 receptors (Harvey and Lacey, 1997). Finally, presynaptic metabotropic Glu receptors are also able to inhibit Glu release to the NAc (Manzoni et al., 1997). The purpose of this study was to identify the adaptive changes in the regulation of transmitter release at the excitatory afferents to the NAc during withdrawal from chronic cocaine treatment.

Because a role for adenosine in the long-term changes of synaptic transmission in response to chronic cocaine has been described in the ventral tegmental area (Bonci and Williams, 1996) and there is evidence for complex interactions between DA and adenosine receptors (Ferre et al., 1997; Harvey and Lacey, 1997), we focused on adenosine-mediated presynaptic regulation of excitatory transmission. Presynaptic A1 receptors have a strong inhibitory action on Glu release from prefrontal cortex afferents (Uchimura and North, 1991; Harvey and Lacey, 1997).

In this report, it is shown that withdrawal from chronic cocaine reduces the apparent presynaptic sensitivity to adenosine. When adenosine transporters were blocked, the potency of adenosine to inhibit Glu release was identical in NAc slices from naive and cocaine-withdrawn rats. It is concluded that cocaine withdrawal augments the uptake of adenosine.

\section{MATERIALS AND METHODS}

Parasagittal NAc and hippocampal slices (400 $\mu \mathrm{m}$ thick) were prepared as described previously (Manzoni and Bockaert, 1995; Manzoni et al., 1997) from 4- to 7-week-old male Sprague Dawley rats. The artificial CSF used for all experiments contained (in $\mathrm{mm}$ ): $126 \mathrm{NaCl}, 2.5 \mathrm{KCl}, 1.2$ $\mathrm{MgCl}_{2}, 2.4 \mathrm{CaCl}_{2}, 18 \mathrm{NaHCO}_{3}, 1.2 \mathrm{NaH}_{2} \mathrm{PO}_{4}$, and 11 glucose, and was equilibrated with $95 \% \mathrm{O}_{2}-5 \% \mathrm{CO}_{2}$. Picrotoxin $(100 \mu \mathrm{M})$ was present in all experiments to block $\mathrm{GABA}_{\mathrm{A}}$ synaptic responses. Animals were given once daily intraperitoneal injections of saline or cocaine $(20 \mathrm{mg} / \mathrm{kg})$ for 2 weeks. The animals were tested $1 \mathrm{~d}$ or 1 week after the last cocaine injection. All experiments were done in the absence of cocaine such that slices from cocaine-treated animals were termed cocaine-withdrawn.

To evoke synaptic potentials, stimuli (100 $\mu$ sec duration) were deliv- 
ered at $0.033 \mathrm{~Hz}$ via bipolar stainless steel electrodes placed at the prefrontal-accumbens border (Manzoni et al., 1997). Recordings were made in the rostromedial dorsal accumbens close to the anterior commissure. Whole-cell recordings (Blanton et al., 1989) were made with patch pipettes containing (in $\mathrm{mM}$ ): $122.5 \mathrm{Cs}$ gluconate, $17.5 \mathrm{CsCl}, 10$ HEPES, 0.2 EGTA, $8 \mathrm{NaCl}, 2 \mathrm{MgATP}, 0.2 \mathrm{cAMP}$, and $0.3 \mathrm{Na}_{3} \mathrm{GTP}$, pH 7.2, 290-300 mOsm. Paired-pulse facilitation (PPF) was elicited by stimulating the input twice with a $50 \mathrm{msec}$ interval. An Axopatch-1D (Axon Instruments) was used to record the data, which were filtered at $2 \mathrm{kHz}$, digitized at $5 \mathrm{kHz}$ on a DigiData 1200 interface (Axon Instruments), and collected on a personal computer using ACQUIS-1 software (Bio-Logic). For field potential recordings, both the field EPSP (fEPSP) slope (calculated with a least square method) and fEPSP amplitude were measured. In whole-cell recordings, EPSC amplitudes were measured by averaging a $5 \mathrm{msec}$ window around the peak and subtracting the average value obtained during a $5 \mathrm{msec}$ window immediately before the stimulus. During miniature EPSC (mEPSC) recordings, $1 \mu \mathrm{M}$ tetrodotoxin was added to the CSF. The mEPSCs were detected off-line using software that selected putative mEPSCs according to both their fast rise time and slower decay time (Manzoni et al., 1997). The fitting curves were calculated according to $y=\left\{y_{\max }-y_{\min } / 1+\left(x / \mathrm{EC}_{50}\right)^{\mathrm{n}}\right\}+y_{\min }$ (in which $y_{\max }$ $=$ response in the absence of agonist, $y_{\min }=$ response remaining in presence of maximal agonist concentration, $x=$ concentration, $\mathrm{EC}_{50}=$ concentration of agonist producing $50 \%$ of the maximal response, and $n=$ slope) with Kaleidagraph software (Abelbeck Software). All values are given as mean \pm SEM and are normalized to their relative baseline. Statistical analysis were done with the Mann-Whitney $U$ test using Statview-Student (Abacus Concepts, Calabasas, CA). $p<0.05$ indicated statistical significance. Drugs used are as follows: 8-cyclopentyltheophylline (8-CPT), 8-cyclopentyl-1,3-dipropyl-xanthine (DPCPX), $\mathrm{N}^{6}$-cyclopentyl-adenosine (N6CPA), and RO 20-1724 from Research Biochemicals (Natick, MA); L-CCGI, L-AP-4, and (S)-4C3HPG from Tocris Neuramin; tetrodotoxin, DA, cocaine, S-(4-nitrobenzyl)-6-thioinosine (NBTI), and dipyridamole (DIPY) from Sigma (St. Louis, MO).

\section{RESULTS}

The initial experiments used extracellular field potential recordings to measure the effects of adenosine on synaptic responses evoked by stimulating prefrontal cortex fibers (Nicola et al., 1996; Manzoni et al., 1997). Activation of A1 adenosine receptors cause inhibition at many central synapses (Dunwiddie, 1985; Uchimura and North, 1991; Manzoni et al., 1994; Harvey and Lacey, 1997). We observed that fEPSPs, in the core of the NAc, were strongly inhibited by bath-applied adenosine (data not shown). Adenosine $(50 \mu \mathrm{M})$ reduced the fEPSP to $46.9 \pm 9.3 \%$ of its basal value. This depression was completely blocked by the A1 antagonists 8-CPT $(40 \mu \mathrm{M})$ and DPCPX (200 nM); $50 \mu \mathrm{M}$ adenosine reduced the fEPSP to $96.2 \pm 3.1 \%$ and $112.2 \pm 5.1 \%$ of control in the presence of 8-CPT or DPCPX, respectively ( $p<0.005$; MannWhitney $U$ test, when comparing the inhibitory actions of $50 \mu \mathrm{M}$ adenosine in the presence or absence of 8-CPT or DPCPX; $n=$ 3 and 5, respectively).

Whole-cell patch-clamp experiments indicated that this inhibition was mediated by presynaptic A1 receptors. First, the adenosine-induced depression always caused an increase in the PPF (a presynaptic form of short-term plasticity). Adenosine (50 $\mu \mathrm{M})$ reduced the evoked EPSCs to $45 \pm 11 \%$ of control and increased PPF to $170 \pm 44 \%$ of control $(n=5)$, confirming previous reports (Uchimura and North, 1991; Harvey and Lacey, 1997). Second, adenosine strongly inhibited the frequency of spontaneous mEPSCs without changing their amplitude (Fig. 1C).

Rats were given once daily intraperitoneal injections of saline or cocaine $(20 \mathrm{mg} / \mathrm{kg})$ for 2 weeks. Experiments were done $1 \mathrm{~d}$ or 1 week after the last cocaine injection. In slices prepared from naive rats, adenosine $(30 \mu \mathrm{M} ; 5 \mathrm{~min})$ caused a depression of synaptic transmission of $\sim 50 \%$, whereas in rats withdrawn from cocaine for 1 or $8 \mathrm{~d}$ this concentration of adenosine was without effect (Fig. 1A). Dose-response curves for adenosine were shifted to the right in animals withdrawn from cocaine compared with control, with no change in the maximal adenosine-induced inhibition (Fig. $1 B$ ). Thus, withdrawing rats from chronic cocaine injection had dramatic consequences on A1 presynaptic inhibition of evoked Glu release in the NAc.

Cocaine withdrawal also affected the A1 inhibition of spontaneous Glu release. In naive rats, the frequency of the mEPSCs was reversibly depressed by adenosine $(50 \mu \mathrm{M})$, an effect that was reduced in rats withdrawn from cocaine (Fig. 1C). Withdrawal from cocaine did not modify the average basal mEPSC frequency (control rats, $5.6 \pm 1.2 \mathrm{~Hz} ; n=9$; cocaine-withdrawn rats, $4.8 \pm$ $0.5 \mathrm{~Hz} ; n=9 ; p=0.93$; Mann-Whitney $U$ test). Thus, chronic cocaine treatment resulted in a long-term reduction in the potency of adenosine to presynaptically inhibit transmitter release.

To distinguish between presynaptic changes attributable to a genuine desensitization of presynaptic A1 receptors and modifications independent of A1 receptors, the effect of the selective and metabolically stable adenosine A1 agonist N6CPA was examined. In contrast to what was observed with adenosine, the dose-response curve for N6CPA was the same in control and cocaine-withdrawn slices (Fig. $2 A$ ). This indicates that a decrease in the sensitivity of adenosine A1 receptors was not responsible for the long-term changes induced by cocaine withdrawal.

To test whether the presynaptic effects of adenosine were diminished in other brain regions, hippocampal slices were prepared from the same rats used for the NAc slice experiments. As shown in Figure $2 B$, at the Schaffer collateral-CA1 pyramidal cells synapse, adenosine-induced presynaptic inhibition of Glu release was normal in rats withdrawn from cocaine, suggesting that this effect is indeed specific to the NAc.

To further investigate the consequences of cocaine withdrawal in the NAc, the effects of activation of dopamine D1 and metabotropic Glu receptors (mGluRs) were examined (Nicola et al., 1996; Manzoni et al., 1997). The inhibition of fEPSP caused by cocaine $(30 \mu \mathrm{M} ; 10 \mathrm{~min})$ and DA $(100 \mu \mathrm{M} ; 10 \mathrm{~min})$ was not different in slices from control and cocaine-withdrawn rats (Table 1). In addition, the inhibition caused by presynaptic mGluRs was not changed after chronic cocaine treatment. Neither the inhibition induced by the selective group 3 mGluR agonist L-AP-4 nor by the selective group $2 \mathrm{mGluR}$ agonists L-CCG1 and (S)4C3HPG was modified after withdrawal (Table 1). Together, these observations excluded a general decrease of presynaptic inhibition as a possible explanation for the effect of cocaine withdrawal.

Acute withdrawal from cocaine and morphine lead to an upregulation in the cAMP-dependent cascade in several areas of the brain (Nestler and Aghajanian, 1997). Biochemical studies (Terwilliger et al., 1991; Self and Nestler, 1995; but see Mayfield et al., 1992) have indicated an overall upregulation of the cAMPdependent cascade in the NAc in response to chronic cocaine treatment. The role of the cAMP cascade during cocaine withdrawal was examine by application of the adenylate cyclase (AC) activator forskolin (FSK) $(10 \mu \mathrm{M} ; 20 \mathrm{~min})$ (Seamon and Daly, 1986). FSK caused a potentiation of fEPSPs in control rats (Fig. $3 A$ ) that was not changed in rats withdrawn from cocaine (Fig. $3 A)$. The inactive FSK analog dideoxy-FSK (10 $\mu \mathrm{M} ; 10 \mathrm{~min})$ was without effect (data not shown), indicating that the effects of FSK were attributable to AC activation. The FSK-induced enhancement was potentiated when slices were preincubated in the presence of the adenosine A1 antagonist DPCPX (200 nM), indicating that the metabolism of cAMP is one important source of extracellular adenosine in NAc slice, as reported previously in the 


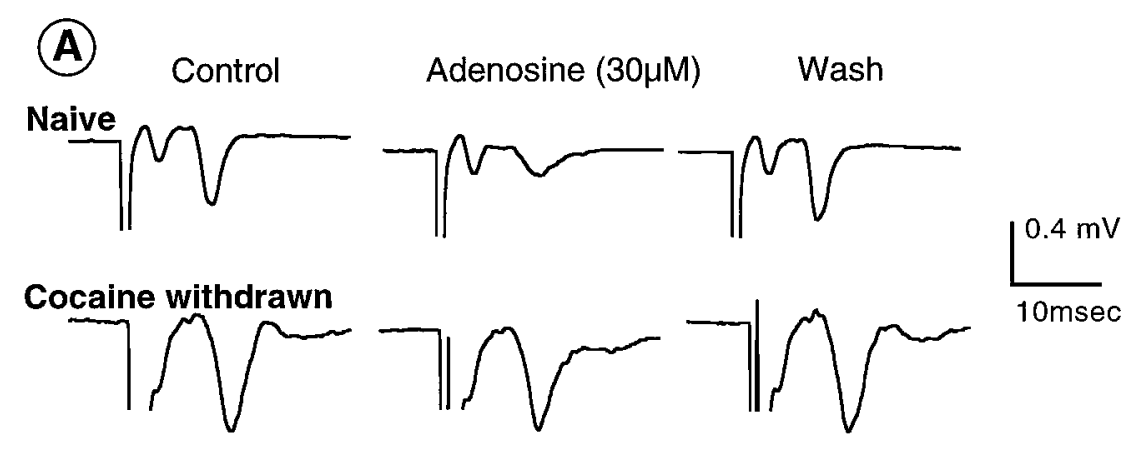

Figure 1. Reduction of A1 adenosine presynaptic inhibition in the NAc of rats withdrawn from cocaine. $A$, Thirty micromolar adenosine reduced the fEPSP to $50 \pm 7 \%$ $(n=7)$ of its basal value in naive rats (top traces). In rats withdrawn from cocaine for $1 \mathrm{~d}$ (bottom traces), $30 \mu \mathrm{M}$ adenosine reduced the fEPSP to $82 \pm 7 \%$ of its basal value. Traces represent averages of 10 consecutive EPSPs. $B$, Withdrawal from cocaine reduced the potency of adenosine to inhibit Glu release. The $\mathrm{EC}_{50}$ values for adenosine was $32 \pm 4 \mu \mathrm{M}(n=9)$ in control rats, $70 \pm$ $9 \mu \mathrm{M}(n=9)$ after $1 \mathrm{~d}$ withdrawal, and $166 \pm$ $3 \mu \mathrm{M}(n=8)$ after $8 \mathrm{~d}$ withdrawal. Each point is expressed as the percentage of control responses in the absence of agonist, and the error bars represent SEM. C, Cocaine withdrawal reduced the inhibitory effects of adenosine of spontaneous Glu release. In control rats ( filled circles), the mEPSCs frequency was reduced to $35.9 \pm 5.8 \%$ of its baseline value $(n=7)$, whereas the mEPSCs amplitude remained unchanged (94.7 \pm $4.7 \%$ of control). Withdrawal from cocaine did not modify the average basal mEPSCs frequency (control rats, $5.6 \pm 1.2 \mathrm{~Hz} ; n=9$; cocaine-withdrawn rats, $4.8 \pm 0.5 \mathrm{~Hz} ; n=9$; $p=0.93$; Mann-Whitney $U$ test) but clearly reduced the amount of inhibition induced by $50 \mu \mathrm{M}$ adenosine (open circles); the maximal inhibition of the mEPSCs frequency was $68.7 \pm 7.1 \%(n=8)$, with no change in mEPSCs amplitude.

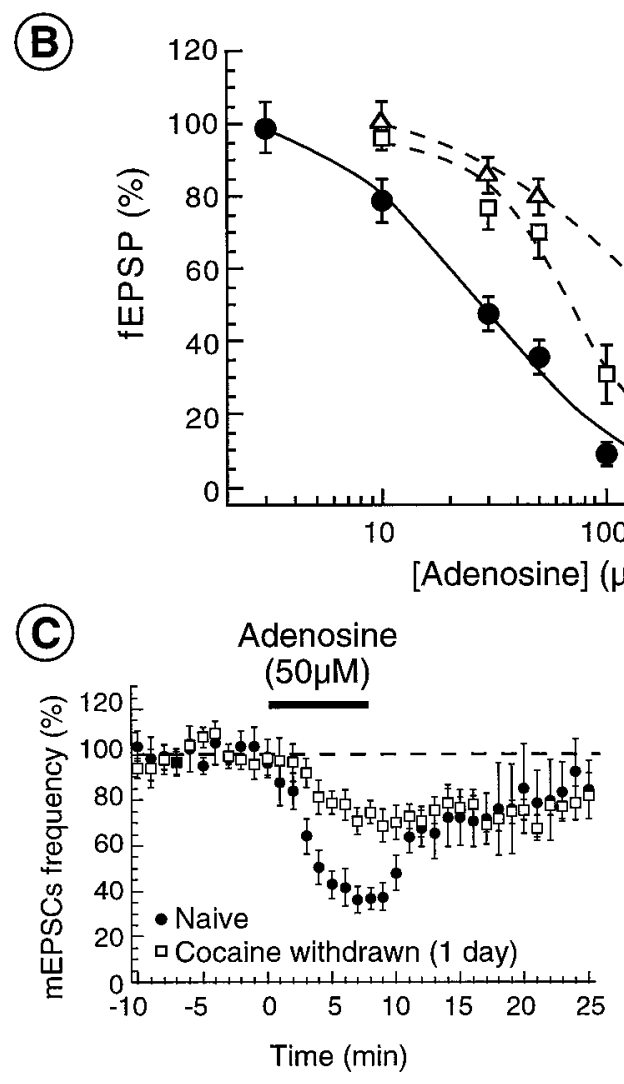

hippocampus (Dunwiddie and Hoffer, 1980; Brundege et al., 1997; Dunwiddie et al., 1997). The DPCPX-induced potentiation was similar in naive and withdrawn rats (Fig. $3 B$ ). Thus, withdrawal from chronic cocaine did not cause an upregulation of AC at the excitatory synapses to the NAc.

The levels of endogenous adenosine depend on the activity of adenosine-forming and adenosine-degrading enzymes (Brundege and Dunwiddie, 1997). In addition, adenosine uptake is an important mechanism that controls the extracellular levels of adenosine in the brain (Dunwiddie and Hoffer, 1980; Dunwiddie, 1985; Dunwiddie and Diao, 1994; Brundege and Dunwiddie, 1997; Brundege et al., 1997; Dunwiddie et al., 1997). Adenosine levels were estimated by measuring the increases of the EPSCs amplitude caused by the A1 antagonists 8-CPT and DPCPX. When uptake mechanisms were fully active, the effects of A1 antagonists were small, indicating rather low tonic extracellular levels of adenosine in both naive and cocaine-withdrawn rats (Fig. 4A). The source of this basal level of adenosine was examined using the cAMP-dependent phosphodiesterase inhibitor RO 20-1724 (Beavo and Reifsnyder, 1990). As shown in Figure 4A,
RO 20-1724 caused an increase of the fEPSP to an extent similar to what was observed with the A1 antagonist in both naive and cocaine-withdrawn slices. In addition, preincubation with DPCPX totally occluded the RO 20-1724 enhancement (Fig. 4A). The results support the hypothesis that the metabolism of cAMP is one primary source of extracellular adenosine in the NAc.

In hippocampal slices, the adenosine uptake inhibitors DIPY and NBTI have been shown to depress the fEPSP by increasing the extracellular adenosine concentration (Dunwiddie and Hoffer, 1980; Dunwiddie and Diao, 1994). Accordingly, in both naive and cocaine-withdrawn rats, this combination of uptake inhibitors caused a strong inhibition of excitatory synaptic transmission that was be totally antagonized by the adenosine A1 antagonist DPCPX (Fig. 4B). Thus, adenosine uptake is essential to control low extracellular levels of adenosine in the NAc, as has been found in the hippocampus (Dunwiddie and Hoffer, 1980; Dunwiddie and Diao, 1994).

The possibility that chronic cocaine treatment could result in an upregulation of adenosine uptake was tested in experiments with reuptake inhibitors (Dunwiddie and Diao, 1994). Treatment 


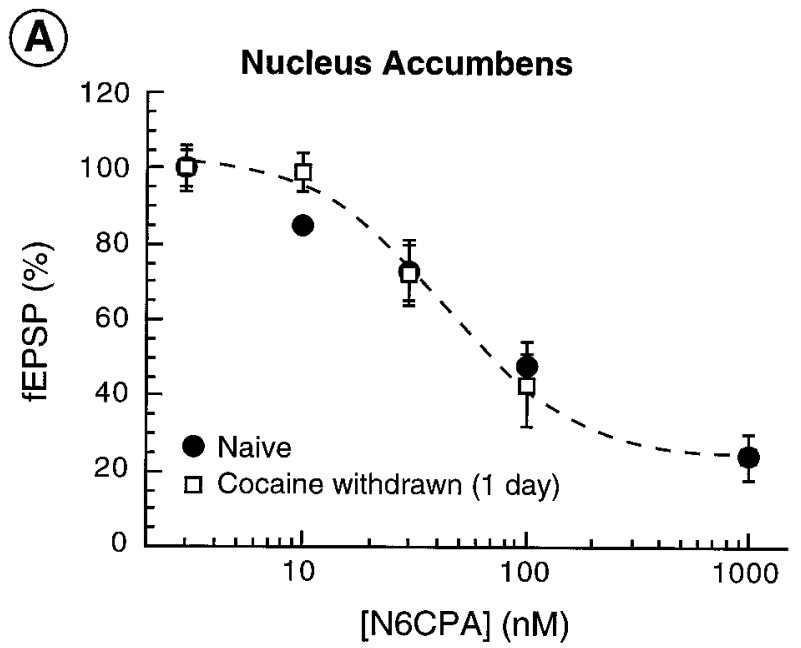

(B)

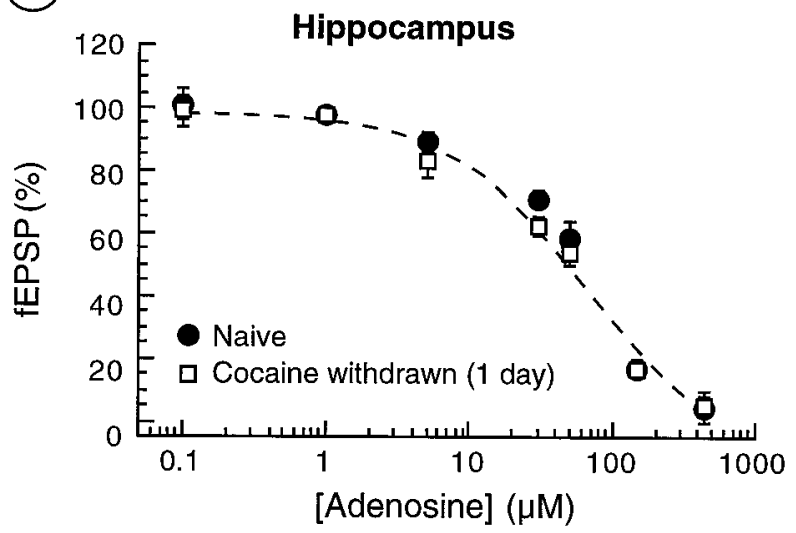

Figure 2. The potency of the selective and metabolically stable adenosine A1 agonist N6CPA was the same in control and cocaine-withdrawn slices (1 $\mathrm{d}$ withdrawal). $A$, The $\mathrm{EC}_{50}$ values for N6CPA were $43 \pm 9 \mathrm{~nm}$ in slices prepared from naive rats and $47 \pm 16 \mu \mathrm{M}$ in slices from withdrawn rats $(n=$ 5 and 7, respectively). $B$, The presynaptic effects of adenosine were not diminished in the hippocampus. Both NAc and hippocampus slices were prepared from the same animals. At the Schaffer collateral-CA1 pyramidal cells synapse of cocaine-withdrawn rats, adenosine-induced presynaptic inhibition of Glu release was similar to what was observed in naive rats; the $\mathrm{EC}_{50}$ values were $68 \pm 4 \mu \mathrm{M}(n=5)$ and $53 \pm 4 \mu \mathrm{M}(n=5)$, respectively.

\section{Table 1. Effect of cocaine withdrawal}

\begin{tabular}{|c|c|c|}
\hline \multirow[b]{2}{*}{ Drugs } & \multicolumn{2}{|l|}{ fEPSP $(\%)$} \\
\hline & Naive & Cocaine-withdrawn \\
\hline $\mathrm{DA}, 100 \mu \mathrm{M}$ & $59 \pm 5(n=14)$ & $62 \pm 8(n=14)$ \\
\hline Cocaine, $30 \mu \mathrm{M}$ & $42 \pm 6(n=$ & $41 \pm 8(n=16)$ \\
\hline L-AP-4, $10 \mu \mathrm{M}$ & $58 \pm 10(n=6)$ & $64 \pm 10(n=6)$ \\
\hline $\mathrm{L}-\mathrm{CCG} 1,5 \mu \mathrm{M}$ & $55 \pm 7(n=5)$ & $60 \pm 5(n=5)$ \\
\hline (S)-4C3HPG, $50 \mu \mathrm{M}$ & $58 \pm 14(n=6)$ & $64 \pm 15(n=6)$ \\
\hline
\end{tabular}

$\overline{\text { One day withdrawal from cocaine does not change cocaine, DA, or mGluR-induced }}$ presynaptic depression in the NAc.

with the uptake blockers NBTI and DIPY caused a large depression of the fEPSP (Fig. 4B). Under these conditions, accumulation of endogenous adenosine reduced the fEPSP to the point that a precise measure of the effects of exogenously applied adenosine was not possible. To reduce levels of endogenous
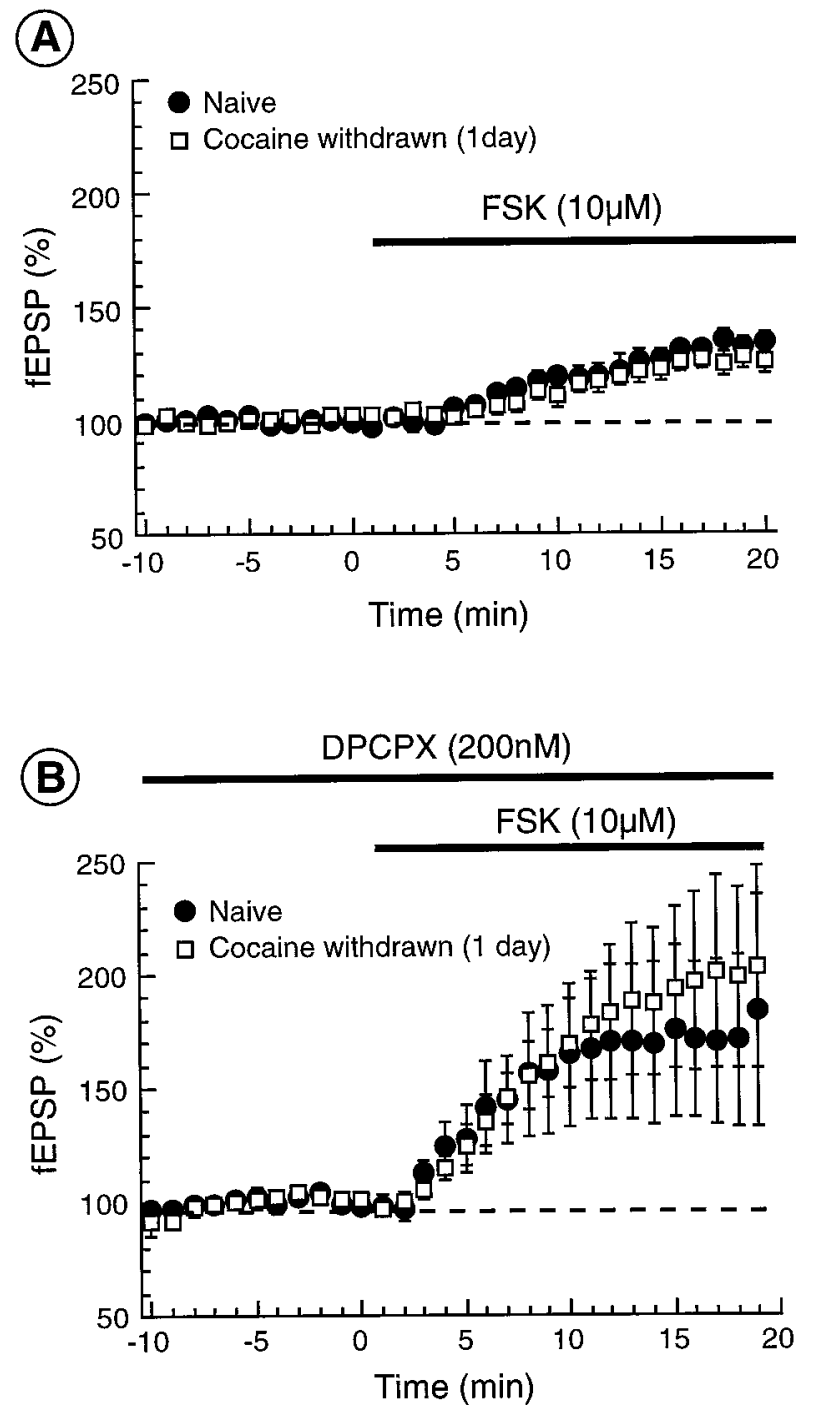

Figure 3. Withdrawal from cocaine did not cause an upregulation of the AC at the excitatory terminal to the NAc. $A$, The AC activator FSK caused a similar augmentation of the EPSC in naive ( filled circles; $n=8$ ) and cocaine-withdrawn ( $1 \mathrm{~d}$ withdrawal) (open squares; $n=9$ ) slices. $B$, The FSK-induced enhancement was potentiated by the adenosine A1 antagonist DPCPX to a similar extend in naive (filled circles; $n=5$ ) and cocaine-withdrawn (open squares; $n=5$ ) slices.

adenosine, slices were preincubated with RO 20-1724 (200 $\mu \mathrm{M})$ to block adenosine production from cAMP metabolism. This greatly reduced the inhibition induced by the uptake blockers (Fig. 5A). This observation confirms that phosphodiesterasemediated degradation of CAMP is a major source of extracellular adenosine in the NAc.

By reducing the endogenous concentration of adenosine, the sensitivity of A1 receptors to exogenously applied adenosine could be determined. As shown in Figure $5 B$, with adenosine uptake blocked, the potency of adenosine to inhibit excitatory synaptic transmission was similar in slices from naive and cocaine-withdrawn rats (Fig. $5 B$ ). Thus, inhibition of adenosine reuptake reversed the "cocaine-withdrawn phenotype".

\section{DISCUSSION}

This report suggests that cocaine withdrawal augments adenosine uptake to decrease the potency of adenosine-mediated inhibition 


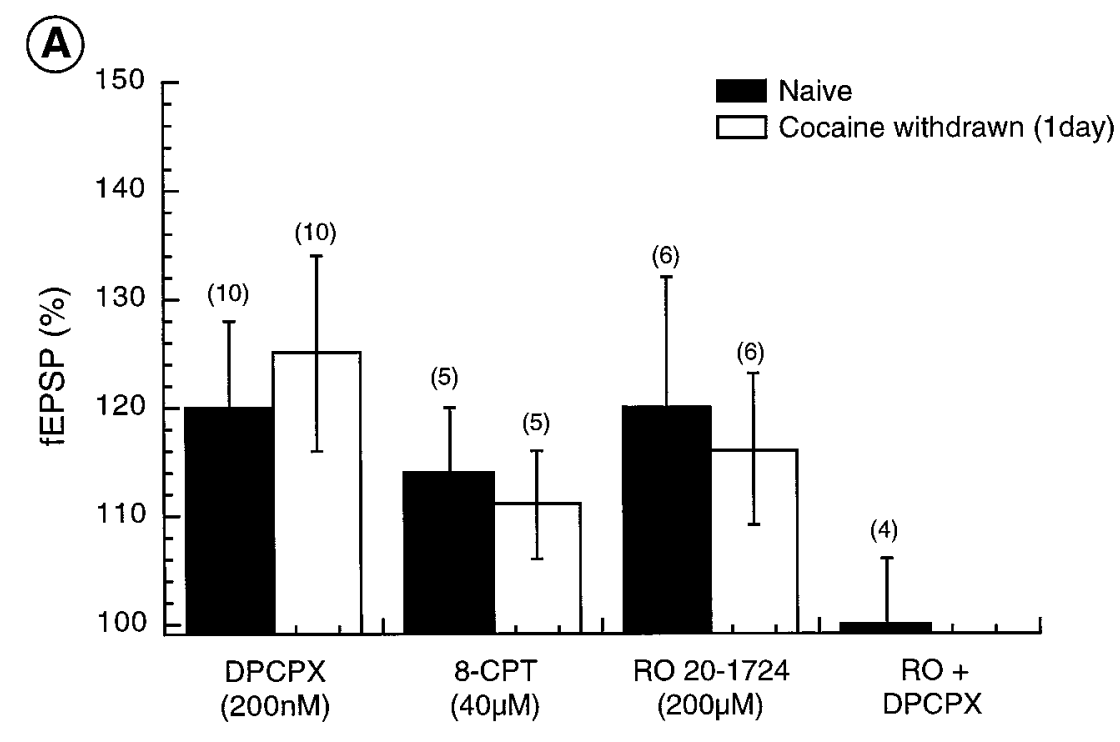

Figure 4. Endogenous adenosine levels are regulated by metabolism and reuptake. $A$, The A1 antagonists moderately increased the fEPSP, showing low endogenous extracellular levels of adenosine in both naive and cocaine-withdrawn rats. The cAMP-dependent phosphodiesterase inhibitor RO 20-1724 caused an increase of the fEPSP similar to what was observed with the A1 antagonists in both naive and cocaine-withdrawn slices (1 d withdrawal). Preincubation with DPCPX totally occluded the RO 20-1724 enhancement. $B$, The adenosine uptake inhibitors DIPY and NBTI depress the fEPSP by increasing the extracellular adenosine concentration; in both naive $(n=8)$ and cocainewithdrawn $(n=6)$ rats, the uptake inhibitors caused a strong inhibition of the fEPSP that was totally antagonized by DPCPX.

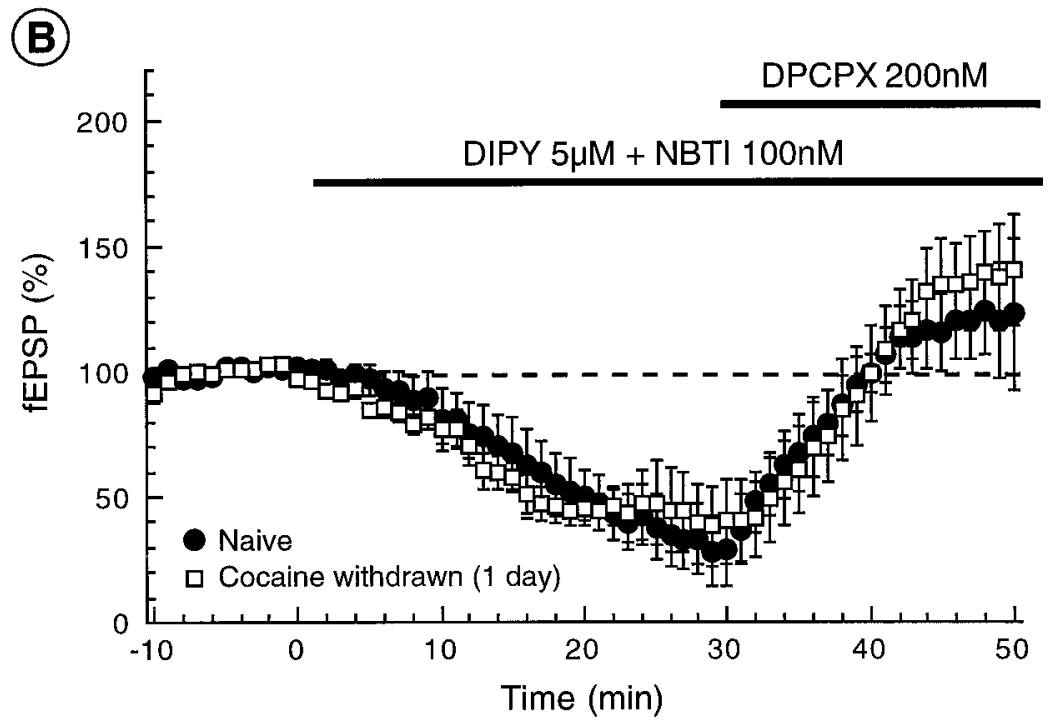

of Glu release. This result predicts that the enhanced adenosine uptake will ultimately increase Glu release to increase the excitability of medium spiny neurons. In fact, increased Glu release has been observed in the NAc of cocaine-sensitized rats (Pierce et al., 1996), and the mechanisms described in the present report may contribute to the adaptive responses to chronic cocaine. Modulation of the excitatory inputs of the NAc is significant, because medium spiny neurons are essentially quiescent and their activity is dependent on glutamatergic excitation (Pennartz et al., 1994).

Presynaptic inhibition by adenosine A1 receptors is widespread in the CNS (Dunwiddie, 1985; Brundege and Dunwiddie, 1997). In addition to the known effects of adenosine on PPF (Harvey and Lacey, 1997), this report shows that adenosine strongly decreases the frequency of mEPSCs, reinforcing the idea that A1 receptors mediate strong presynaptic depression of Glu release from excitatory afferents in the NAc.

In addition to A1 receptors, D1 dopamine receptors and group 2/3 mGluRs are known to inhibit Glu release at presynaptic sites in the NAc (Nicola et al., 1996; Manzoni et al., 1997). The apparent diminution of A1 inhibition may be explained by a general decrease of presynaptic inhibition in response to chronic cocaine, based on a decrease in $\mathrm{G}_{\mathrm{i}} \alpha$ and $\mathrm{G}_{\mathrm{o}} \alpha$ in the NAc (Terwilliger et al., 1991). However, chronic cocaine did not change the inhibitory effects of D1 dopamine, group 2/3 mGluRs receptors, or metabolically stable adenosine receptor agonists. Thus, a change in presynaptic receptor coupling to inhibition is unlikely.

One important aspect of this study is that the cocaine-induced alteration of the adenosine uptake was present for at least $8 \mathrm{~d}$ after withdrawal. The fact that presynaptic inhibition by adenosine was not modified in the hippocampus suggests that this effect of chronic cocaine selectively affected the NAc, a structure thought to be involved in drug abuse behaviors. Further regional specificity is suggested by the observation that an upregulation of adenosine tone in response to chronic cocaine was found in the ventral tegmental area (Bonci and Williams, 1996). Using a similar approach, such an increase was not detected in the present study. This result indicates marked regional specificity of the cocaine-induced adaptations of the adenosine systems.

This study also contrasts with reports suggesting an overall 


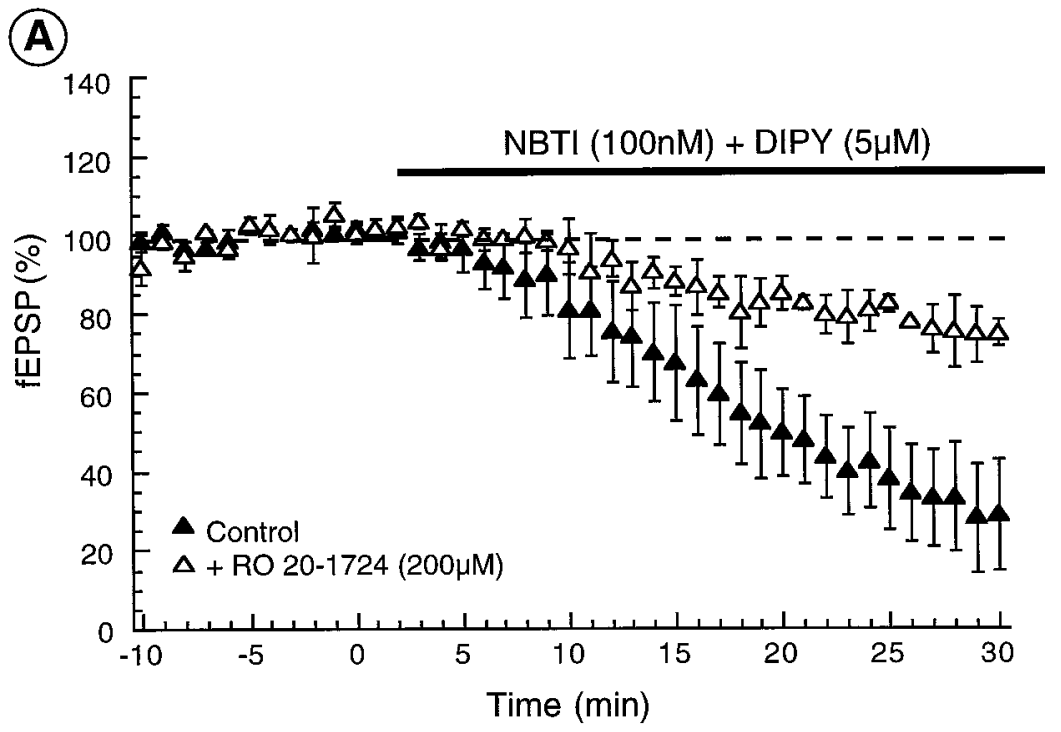

(B)

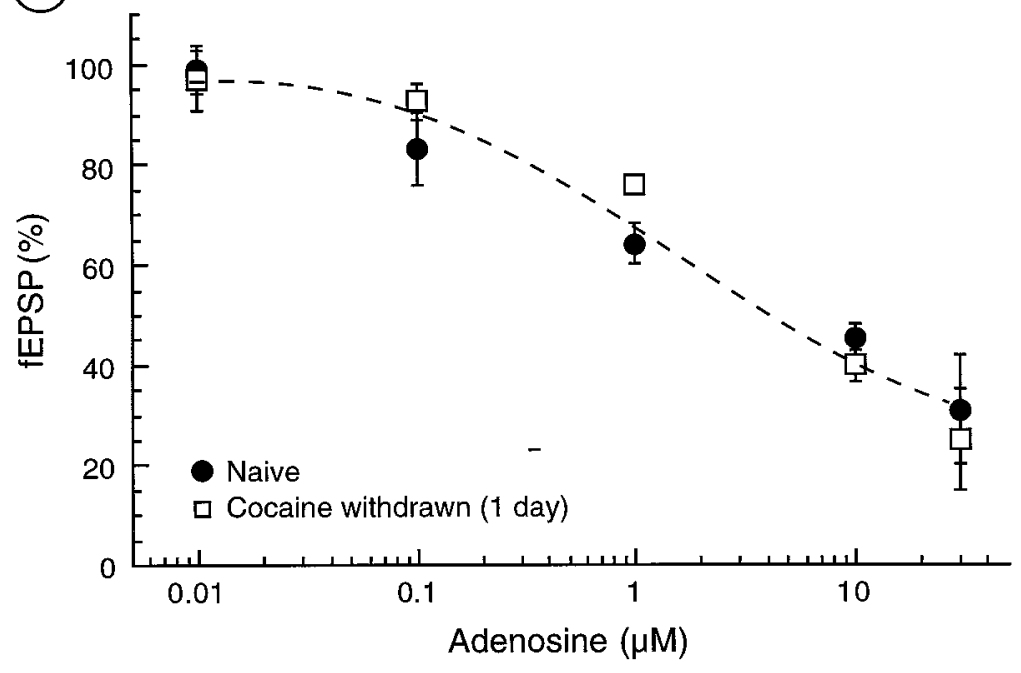

Figure 5. Role of uptake in regulating adenosine levels in cocaine-withdrawn rats. $A$, Phosphodiesterase-mediated degradation of cAMP is an important source of extracellular adenosine in the NAc. The inhibition induced by the uptake blockers NBTI plus DIPY $(n=6)$ was greatly reduced when slices were preincubated with RO 20-1724 $(200 \mu \mathrm{M} ; n=6)$ to block adenosine production from cAMP metabolism. $B$, When adenosine uptake was blocked by a mixture of NBTI plus DIPY and endogenous adenosine formation was reduced with RO 20-1724, the potency of adenosine to inhibit excitatory synaptic transmission was similar in naive and chronic cocaine rats after $1 \mathrm{~d}$ of withdrawal. The $\mathrm{EC}_{50}$ values were $2.1 \pm 5.5 \mu \mathrm{M}(n=5)$ and $4.8 \pm 0.4 \mu \mathrm{M}(n=6)$ for naive and cocaine-withdrawn slices, respectively. upregulation of the cAMP-dependent cascade in the NAc in response to chronic cocaine treatment (Terwilliger et al., 1991; Self and Nestler, 1995; for review, see Nestler et al., 1996; Nestler and Aghajanian, 1997; Self et al., 1998). Although the cAMP pathway does affect synaptic release at this excitatory glutamatergic synapse to medium spiny neurons in the NAc (Fig. 3), the regulation of this pathway through the cAMP cascade was not affected during withdrawal from chronic cocaine treatment. This observation is consistent with biochemical studies showing that neither basal nor DA-stimulated AC activity was affected by chronic cocaine in the NAc (Mayfield et al., 1992).

The main source of adenosine in the NAc is the degradation of cAMP by a RO 20-1724-sensitive cAMP-dependent phosphodiesterase, which is not changed during cocaine withdrawal. This seems to be a specific feature of the NAc, because phosphodiesterase inhibitors have little effect on the extracellular levels of adenosine in the hippocampal slices preparation (S. Masino and T. Dunwiddie, personal communication). Inhibition of cAMPdependent phosphodiesterase considerably reduced the extracellular accumulation of adenosine induced by the uptake blockers. Thus, the accurate measurement of the sensitivity to exogenous adenosine was enabled. In these conditions, we found that the potency of adenosine to inhibit excitatory transmission was identical in naive and cocaine-withdrawn rats. The simplest interpretation of the results is that withdrawal from cocaine caused the upregulation of adenosine transporters in the NAc. Biochemical experiments have shown an upregulation of adenosine transporter-binding sites in the striatum in opiate-tolerant mice (Kaplan and Leite-Morris, 1997). Together with the present report, this suggests that adenosine transporters might be a common target for drug of abuse-induced neuronal plasticity. The cloning of several nucleoside-adenosine transporters (Pajor and Wright, 1992; Huang et al., 1994; Griffiths et al., 1997a,b; Ritzel et al., 1997; Yao et al., 1997) may help determine the molecular mechanisms underlying the susceptibility of NAc adenosine transporters to cocaine-induced modifications.

Although the initial effects of acute cocaine are attributable to the blockade of monoamine transporters leading to an increase in extracellular DA (presumably followed by activation of dopamine receptors), part of the long-term consequences of withdrawal from chronic cocaine might be on neuromodulators unrelated to the primary targets of cocaine. This concept is consistent with previous reports showing upregulated adenosine metabolism in response to chronic cocaine in the ventral tegmental area (Bonci 
and Williams, 1996). Moreover, dopamine D1 receptor-mediated presynaptic inhibition of excitatory transmission in the NAc seems to be, in part, attributable to the D1-dependent release of adenosine from medium spiny neurons (Harvey and Lacey, 1997; Nicola and Malenka, 1997), suggesting complex cross talk between adenosine A1 and dopamine D1 receptors (for review, see Ferre et al., 1997).

\section{REFERENCES}

Beavo JA, Reifsnyder DH (1990) Primary sequence of cyclic nucleotide phosphodiesterase isozymes and the design of selective inhibitors. Trends Pharmacol Sci 11:150-155.

Blanton MG, Lo Turco JJ, Kriegstein AR (1989) Whole cell recording from neurons in slices of reptilian and mammalian cerebral cortex. J Neurosci Methods 30:203-210.

Bonci A, Williams JT (1996) A common mechanism mediates long-term changes in synaptic transmission after chronic cocaine and morphine. Neuron 16:631-639.

Brundege JM, Dunwiddie TV (1997) Role of adenosine as a modulator of synaptic activity in the central nervous system. Adv Pharmacol 39:353-391.

Brundege JM, Diao LH, Proctor WR, Dunwiddie TV (1997) The role of cyclic AMP as a precursor of extracellular adenosine in the rat hippocampus. Neuropharmacology 36:1201-1210.

Dunwiddie TV (1985) The physiological role of adenosine in the central nervous system. Int Rev Neurobiol 27:63-139.

Dunwiddie TV, Diao L (1994) Extracellular adenosine concentrations in hippocampal brain slices and the tonic modulation of evoked excitatory responses. J Pharmacol Exp Ther 268:537-548.

Dunwiddie TV, Hoffer BJ (1980) Adenine nucleotides and synaptic transmission in the in vitro rat hippocampus. Br J Pharmacol 69:59-68.

Dunwiddie TV, Diao L, Proctor WR (1997) Adenine nucleotides undergo rapid, quantitative conversion to adenosine in the extracellular space in rat hippocampus. J Neurosci 17:7673-7682.

Ferre S, Fredholm BB, Morelli M, Popoli P, Fuxe K (1997) Adenosinedopamine receptor-receptor interactions as an integrative mechanism in the basal ganglia. Trends Neurosci 20:482-487.

Griffiths M, Beaumont N, Yao SY, Sundaram M, Boumah CE, Davies A, Kwong FY, Coe I, Cass CE, Young, JD, Baldwin SA (1997a) Cloning of a human nucleoside transporter implicated in the cellular uptake of adenosine and chemotherapeutic drugs. Nat Med 3:89-93.

Griffiths M, Yao S, Abidi F, Phillips, SE, Cass CE, Young JD, Baldwin SA (1997b) Molecular cloning and characterization of a nitrobenzylthioinosine-insensitive (ei) equilibrative nucleoside transporter from human placenta. Biochem J 328:739-743.

Harvey J, Lacey MG (1997) A postsynaptic interaction between dopamine D1 and NMDA receptors promotes presynaptic inhibition in the rat nucleus accumbens via adenosine release. J Neurosci 17:5271-5280.

Huang QQ, Yao SY, Ritzel MW, Paterson AR, Cass CE, Young JD (1994) Cloning and functional expression of a complementary DNA encoding a mammalian nucleoside transport protein. J Biol Chem 269:17757-17760.

Hyman SE (1996) Addiction to cocaine and amphetamine. Neuron 16:901-904.

Kalivas PW, Duffy P (1990) The effect of acute and daily cocaine treatment on extracellular dopamine in the nucleus accumbens. Synapse $5: 48-58$.

Kaplan GB, Leite-Morris KA (1997) Up-regulation of adenosine transporter-binding sites in the striatum and hypothalamus of opiate tolerant mice. Brain Res 25:215-220.

Kombian SB, Malenka RC (1994) Simultaneous LTP of non-NMDA and LTD of NMDA-receptor-mediated responses in the nucleus accumbens. Nature 368: 242-246.

Koob GF (1992) Drugs of abuse: anatomy, pharmacology and function of reward pathways. Trends Pharmacol Sci 13:177-184.

Koob GF (1996) Drug addiction: the yin and yang of hedonic homeostasis. Neuron 16:893-896.

Manzoni O, Bockaert J (1995) Metabotropic glutamate receptors inhibiting excitatory synapses in the CA1 area of rat hippocampus. Eur J Neurosci 7:2518-2523.

Manzoni O, Michel JM, Bockaert J (1997) Metabotropic glutamate receptors in the rat nucleus accumbens. Eur J Neurosci 9:1514-1523.
Manzoni OJ, Manabe T, Nicoll RA (1994) Release of adenosine by activation of NMDA receptors in the hippocampus. Science 265: 2098-2101.

Mayfield RD, Larson G, Zahniser NR (1992) Cocaine-induced behavioral sensitization and D1 dopamine receptor function in rat nucleus accumbens and striatum. Brain Res 573:331-335.

Nestler EJ, Aghajanian GK (1997) Molecular and cellular basis of addiction. Science 278:58-63.

Nestler EJ, Berhow MT, Brodkin ES (1996) Molecular mechanisms of drug addiction: adaptations in signal transduction pathways. Mol Psychiatry 1:190-199.

Nicola SM, Malenka RC (1997) Dopamine depresses excitatory and inhibitory synaptic transmission by distinct mechanisms in the nucleus accumbens. J Neurosci 17:5697-5710.

Nicola SM, Kombian SB, Malenka RC (1996) Psychostimulants depress excitatory synaptic transmission in the nucleus accumbens via presynaptic D1-like dopamine receptors. J Neurosci 16:1591-1604.

Nie ZG, Madamba SG, Siggins GR (1994) Ethanol inhibits glutamatergic neurotransmission in nucleus accumbens neurons by multiple mechanisms. J Pharmacol Exp Ther 271:1566-1573.

Pajor AM, Wright EM (1992) Cloning and functional expression of a mammalian $\mathrm{Na}^{+}$/nucleoside cotransporter. J Biol Chem 267: $3557-3560$.

Pennartz CM, Boeijinga PH, Lopes de Silva FH (1990) Locally evoked potentials in slices of the rat nucleus accumbens: NMDA and nonNMDA receptor mediated components and modulatory by GABA. Brain Res 529:30-41.

Pennartz CM, Ameerun RF, Groenewegen HJ, Lopes de Silva FH (1993) Synaptic plasticity in an in vitro slice preparation of the rat nucleus accumbens. Eur J Neurosci 5:107-117.

Pennartz CM, Groenewegen HJ, Lopes de Silva FH (1994) The nucleus accumbens as a complex of functionally distinct neuronal ensembles: an integration of behavioral, electrophysiological and anatomical data. Prog Neurobiol 42:719-761.

Pierce RC, Bell K, Duffy P, Kalivas PW (1996) Repeated cocaine augments excitatory amino acid transmission in the nucleus accumbens only in rats having developed behavioral sensitization. J Neurosci 16:1550-1560.

Pontieri FE, Tanda G, Orzi F, Di Chiara G (1996) Effects of nicotine on the nucleus accumbens and similarity to those of addictive drugs. Nature 382:255-257.

Ritzel MW, Yao SY, Huang MY, Elliott JF, Cass CE, Young JD (1997) Molecular cloning and functional expression of cDNAs encoding a human $\mathrm{Na}^{+}$-nucleoside cotransporter (hCNT1). Am J Physiol 272:707-714.

Samson HH, Harris AR (1992) Neurobiology of alcohol abuse. Trends Pharmacol Sci 13:206-211.

Seamon KB, Daly JW (1986) Forskolin: its biological and chemical properties. Adv Cyclic Nucleotide Protein Phosphorylation Res 20:1-150.

Self DW, Nestler EJ (1995) Molecular mechanisms of drug reinforcement and addiction. Annu Rev Neurosci 18:463-495.

Self DW, Genova LM, Hope BT, Banrhart WJ, Spencer JJ, Nestler EJ (1998) Involvement of cAMP-dependent protein kinase in the nucleus accumbens in cocaine self-administration and relapse of cocaineseeking behavior. J Neurosci 18:1848-1859.

Smith DA, Bolam PJ (1990) The neural network of the basal ganglia as revealed by the study of synaptic connections of identified neurones. Trends Neurosci 13:259-266.

Terwilliger RZ, Beitner-Johnson D, Sevarino KA, Crain SM, Nestler EJ (1991) A general role for adaptations in G-proteins and the cyclic AMP system in mediating the chronic actions of morphine and cocaine on neuronal function. Brain Res 548:100-110.

Uchimura N, North RA (1991) Baclofen and adenosine inhibit synaptic potentials mediated by GABA and glutamate release in rat nucleus accumbens. J Pharmacol Exp Ther 258:663-668.

Wise RA, Bozarth MA (1987) A psychomotor stimulant theory of addiction. Psychol Rev 4:469-492.

Woolverton WL, Johnson KM (1992) Neurobiology of cocaine abuse. Trends Pharmacol Sci 13:193-200.

Yao SY, Ng AN, Muzyka WR, Griffiths M, Cass CE, Baldwin SA, Young JD (1997) Molecular cloning and functional characterization of nitrobenzylthioinosine (NBMPR)-sensitive (es) and NBMPR-insensitive (ei) equilibrative nucleoside transporter proteins (rENT1 and rENT2) from rat tissues. J Biol Chem 272:28423-28430. 